\title{
Clinical application of the Panjabi neutral zone hypothesis: the Stabilimax NZ posterior lumbar dynamic stabilization system
}

\author{
James J. Yue, M.D., Jens P. Timm, B.S., ${ }^{2}$ Manohar M. Panjabi, Ph.D., ${ }^{1}$ \\ AND JORGE JARAMILLO-DE LA TORRE, M.D. ${ }^{1}$ \\ ${ }^{1}$ Department of Orthopaedics and Rehabilitation, Yale University School of Medicine; and ${ }^{2}$ Applied \\ Spine Technologies, New Haven, Connecticut
}

\begin{abstract}
$\checkmark$ The neutral zone (NZ) is a region of intervertebral motion around the neutral posture where little resistance is offered by the passive spinal column. The NZ appears to be a clinically important measure of spinal stability function. Its size may increase with injury to the spinal column, which in turn may result in spinal instability or low-back pain. Dynamic stabilization systems are designed to support and stabilize the spine while maintaining range of motion (ROM). The Stabilimax NZ device has been designed to reduce the NZ after spinal injury to treat pain while preserving ROM.
\end{abstract}

\author{
KEY WORDS - low-back pain - neutral zone - lumbar spine - spinal stabilization • \\ investigational device
}

$\mathrm{D}$ YNAMIC stabilization systems are designed to support and stabilize the spine while maintaining ROM. Panjabi and colleagues ${ }^{14-18}$ have developed the principle of the NZ, a region of high flexibility either in flexion or extension around the neutral posture position in which there is little resistance to motion.

\section{The NZ and Pain Generation}

Spinal degeneration or injury increases the NZ and, theoretically, causes pain. The Stabilimax NZ device has been designed to reduce the NZ after spinal injury to treat pain while preserving the ROM. An increase in spinal motion associated with injury in this area has been hypothesized by Panjabi and his group ${ }^{16-18}$ to be a possible mechanism of pain generation in the lumbar spine. From a series of biomechanical studies of the spinal column, they have defined the NZ, a region of intervertebral motion around neutral posture, as a clinically important measure of spinal stability.

\section{Subsystems of Spinal Stability}

To understand the NZ principle, it is necessary to understand the three subsystems of spinal stability. As shown in the schematic in Fig. 1, the stabilizing systems of the spine are as follows: 1) the active subsystem (musculoskeletal system); 2) the passive subsystem (the spinal column); and 3 ) the neural system (activation of the active system through neurological control). Under normal conditions, the three subsystems maintain mechanical stability. Dam-

Abbreviations used in this paper: $\mathrm{NZ}$ neutral zone; $\mathrm{ROM}=$ range of motion. age or dysfunction in one subsystem requires the other two to compensate.

Biomechanical Components of the Stabilizing System and Response to Injury

Panjabi et al. ${ }^{19}$ determined that removal of a disc's nucleus produced an increase in flexion, lateral bending, and axial rotation. Other researchers, using similar models of spinal injury, have also observed that degeneration and trauma produced multidirectional laxity in the spinal col$u_{m} n^{1-4,9,11-13}$ (Fig. 2). Panjabi also investigated the contribution of the spinal muscles (active subsystem) to the stability of the spine. After each injury, simulated muscle forces applied to the spinous process reduced the NZ almost to its intact value, without significantly affecting the ROM. These results support the suggestion that the extra work muscles perform in an injured spine is predominantly to restabilize the NZ, not to restrict the overall ROM.

The interconnection of the third spinal stabilizing subsystem (neural control system) has been evaluated by comparing cohorts of patients with back pain to those without it. Marras et al..$^{10}$ have demonstrated that there is a higher level of muscle activity in patients experiencing back pain. This increase in muscle activity is triggered by the neural subsystem's responsibility for maintaining the mechanical stability, which is not being provided by the degenerated passive subsystem.

In recent research in the field of spinal biomechanics, investigators examined the contribution of the musculoskeletal and neural elements to maintaining stability of the spine. The most important observation yielded by these studies is that degeneration or injury of the spinal structures results in an increase of the NZ. When muscles are 


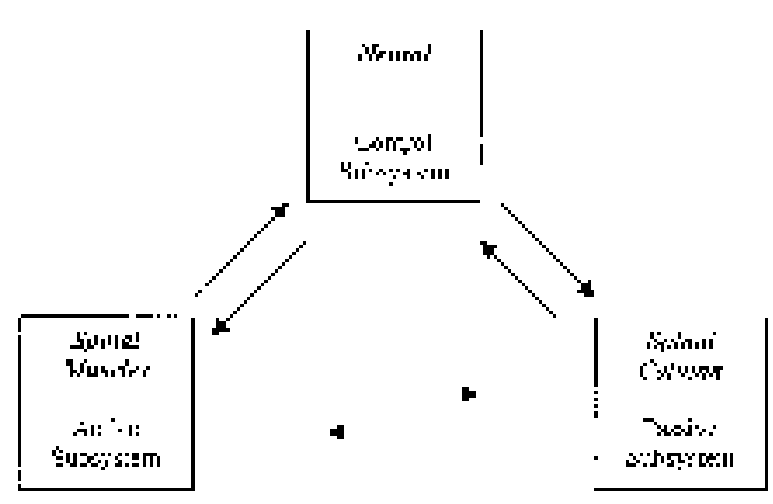

FIG. 1. Schematic showing the spinal stability system and its three subsystems.

recruited to compensate for the laxity of the spine, dysfunction and low-back pain result. ${ }^{5-8}$

\section{The Stabilimax NZ Device}

The Stabilimax NZ device was designed to complement Panjabi's principles of spinal biomechanics. This device, a posterior pedicle screw-based dynamic stabilization system, features dual concentric springs combined with a ball and socket joint, all to enhance spinal stability around neutral posture (Fig. 3). The Stabilimax NZ is designed to increase the resistance of the passive spinal system around neutral posture (the NZ), while maintaining the maximum ROM.

\section{Development Testing}

Initial development testing of the Stabilimax NZ device

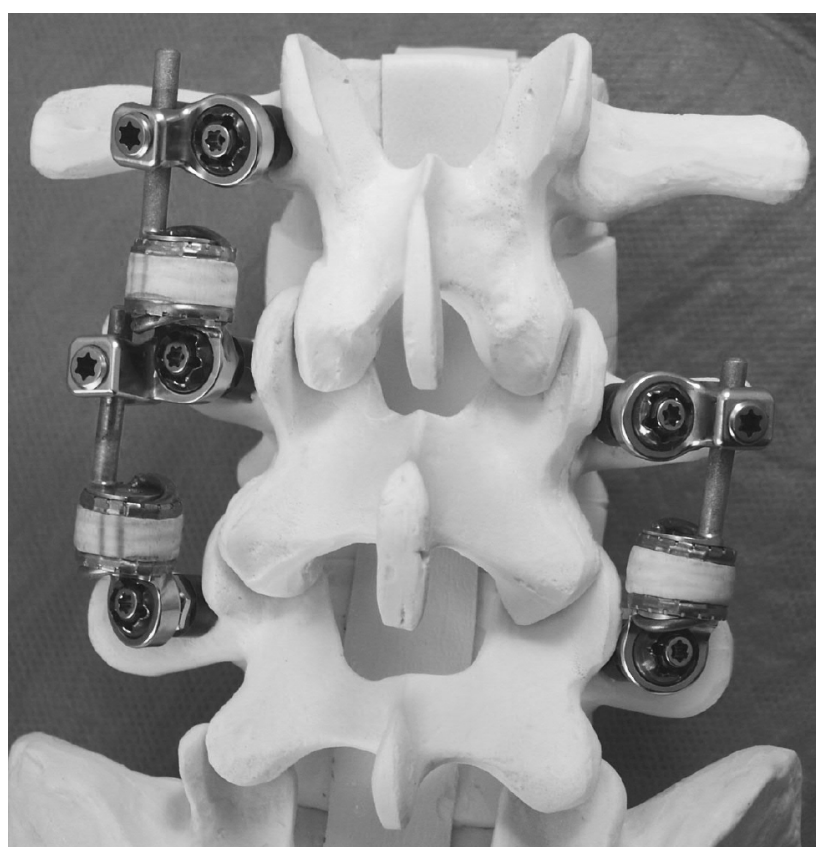

FIG. 3. Photograph of a spine model showing fixation with the Stabilimax NZ device, which contains dual concentric springs combined with two ball and socket joints.

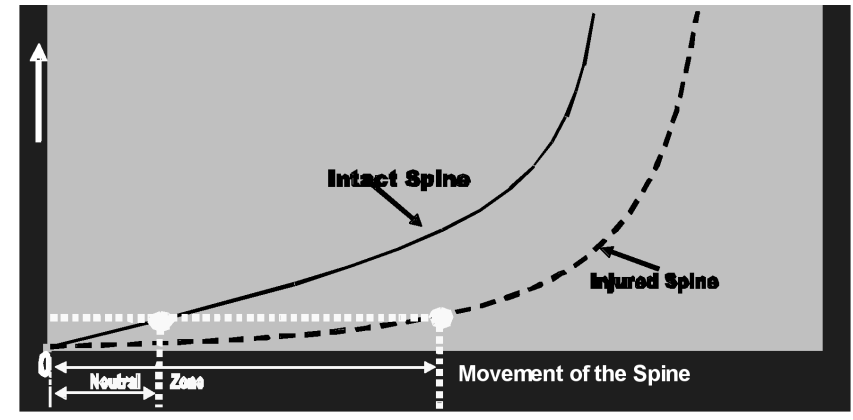

Fig. 2. Graph illustrating the load displacement curve of intact and injured spines. The y axis represents force.

was conducted by Panjabi to determine the optimal device parameters for spring stiffness and interpedicular travel. Subsequent studies were conducted to verify that the load placed on the bone/screw interface by the Stabilimax NZ was less than that of other systems. Additional investigations were performed to measure the effect of the device on NZ and ROM following progressive destabilization procedures.

Regarding optimization of the device characteristics, a study was undertaken to determine the optimal spring stiffness of the device in intact and destabilized spine preparations. Optimal spring stiffness for the device was evaluated in intact spines and in those destabilized by nucleotomy and laminectomy with partial facetectomy. Optimal interpedicular travel of the device was obtained for both compression (spinal extension) and extension (or spinal flexion). Wear testing and in vivo animal testing have also been performed and have verified biocompatibility.

\section{Comparison and Verification Studies}

A comparison study was performed to determine the stress in the screws of the Stabilimax NZ device and to compare it to the stress developed in the screws of two other systems: the Zimmer Dynesys Dynamic Spinal System and the Synthes Universal Spinal Fusion System (results are shown in Fig. 4).

A verification study was performed to evaluate the de-

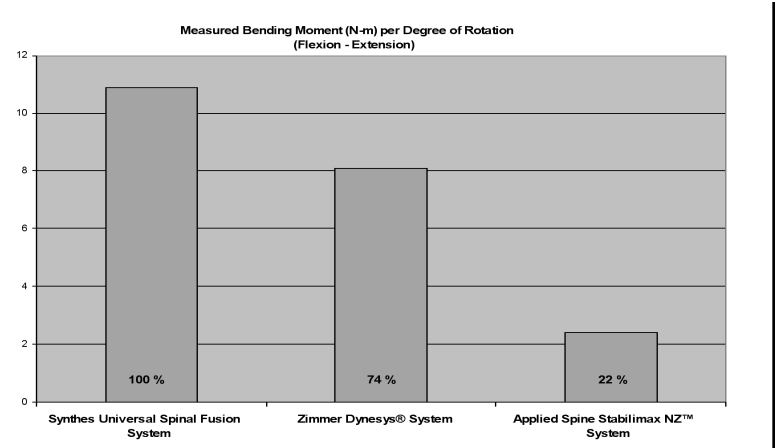

FIG. 4. Bar graph showing measured bending moments for the three systems in a comparison study. The y axis represents Newton meters/degree. 
vice for NZ and ROM in intact and destabilized spines. In this study, NZ and ROM were measured during spinal loading, before and after the device was attached to the lumbar vertebrae. Implantation of the Stabilimax NZ device decreased the NZ during flexion-extension and lateral bending in all states. The study also included measurement of the NZ and ROM in progressive spinal destabilization produced by nucleotomy and laminectomy with partial facetectomy. Both of these procedures increased the NZ and total ROM of the spine, indicating spinal injury or degeneration. Attachment of the Stabilimax NZ device to the spine diminished the NZ while resulting in only a minimal effect on ROM. The results confirm that both the ROM and the NZ increase with progressive spinal injury, and that implantation of the Stabilimax NZ device shrinks the NZ while maintaining overall ROM, meeting a critical design objective.

\section{Conclusions}

Alterations in the NZ have been shown to be associated with the presence of low-back pain. Correction of excessive motion that is a result of an increase in the NZ may theoretically decrease the associated symptoms of lowback pain. The Stabilimax NZ device is designed to remodulate the $\mathrm{NZ}$ and thus provide a more normal ROM around the neutral posture position. Multiple results of laboratory studies indicate correction of abnormal motions and biocompatibility. Clinical trials are planned under an investigational device exemption from the US Food and Drug Administration.

\section{Disclosure}

We (James J. Yue, Jens P. Timm, and Manohar M. Panjabi) are stockholders and consultants for Applied Spine Technologies.

\section{References}

1. Abumi K, Panjabi MM, Kramer KM, Duranceau J, Oxland T, Crisco JJ: Biomechanical evaluation of lumbar spinal stability after graded facetectomies. Spine 15:1142-1147, 1990

2. Ahlgren BD, Lui W, Herkowitz HN, Panjabi MM, Guiboux JP: Effect of anular repair on the healing strength of the intervertebral disc: a sheep model. Spine 25:2165-2170, 2000

3. Ahlgren BD, Vasavada A, Brower RS, Lydon C, Herkowitz HN, Panjabi MM: Anular incision technique on the strength and multidirectional flexibility of the healing intervertebral disc. Spine 19:948-954, 1994

4. Atlas OK, Dodds SD, Panjabi MM: Single and incremental trauma models: a biomechanical assessment of spinal instability. Eur Spine J 12:205-210, 2003
5. Cholewicki J, Crisco JJ III, Oxland TR, Yamamoto I, Panjabi MM: Effects of posture and structure on three-dimensional coupled rotations in the lumbar spine. A biomechanical analysis. Spine 21:2421-2428, 1996

6. Dvorak J, Panjabi MM, Chang DG, Theiler R, Grob D: Functional radiographic diagnosis of the lumbar spine. Flexionextension and lateral bending. Spine 16:562-571, 1991

7. Dvorak J, Panjabi MM, Novotny JE, Chang DG, Grob D: Clinical validation of functional flexion-extension roentgenograms of the lumbar spine. Spine 16:943-950, 1991

8. Dvorak J, Vajda EG, Grob D, Panjabi MM: Normal motion of the lumbar spine as related to age and gender. Eur Spine J 4: 18-23, 1995

9. Kato Y, Panjabi MM, Nibu K: Biomechanical study of lumbar spinal stability after osteoplastic laminectomy. J Spinal Disord 11:146-150, 1998

10. Marras WS, Davis KG, Ferguson SA, Lucas BR, Gupta P: Spine loading charactertistics of patients with low back pain compared with asymptomatic individuals. Spine 26: 2566-2574, 2001

11. Mimura M, Panjabi MM, Oxland TR, Crisco JJ, Yamamoto I, Vasavada A: Disc degeneration affects the multidirectional flexibility of the lumbar spine. Spine 19:1371-1380, 1994

12. Osman SG, Nibu K, Panjabi MM, Marsolais EB, Chaudhary R: Transforaminal and posterior decompressions of the lumbar spine. A comparative study of stability and intervertebral foramen area. Spine 22:1690-1695, 1997

13. Oxland TR, Crisco JJ III, Panjabi MM, Yamamoto I: The effect of injury on rotational coupling at the lumbosacral joint. A biomechanical investigation. Spine 17:74-80, 1992

14. Panjabi MM: Clinical spinal instability and low back pain. J Electromyogr Kinesiol 13:371-379, 2003

15. Panjabi MM: A hypothesis of chronic back pain: ligament subfailure injuries lead to muscle control dysfunction. Eur Spine J 15:668-676, 2006

16. Panjabi MM: The stabilizing system of the spine. Part I. Function, dysfunction, adaptation, and enhancement. J Spinal Disord 5:383-389, 397, 1992

17. Panjabi MM: The stabilizing system of the spine. Part II. Neutral zone and instability hypothesis. J Spinal Disord 5:390-397, 1992

18. Panjabi M, Abumi K, Duranceau J, Oxland T: Spinal stability and intersegmental muscle forces. A biomechanical model. Spine 14:194-200, 1989

19. Panjabi MM, Krag MH, Chung TQ: Effects of disc injury on mechanical behavior of the human spine. Spine 9:707-713, 1984

Manuscript submitted November 2, 2006.

Accepted November 20, 2006.

Address reprint requests to: James J. Yue, M.D., Department of Orthopaedic Surgery and Rehabilitation, Yale University School of Medicine, 800 Howard Avenue, P. O. Box 208071, New Haven, Connecticut 06520. email: james.yue@yale.edu. 